\title{
Enhancing community involvement in tourism: an assessment of the interaction between Ngezi Recreational Park and the surrounding community
}

\author{
Chiedza N. Mutanga ${ }^{1}$, Getrude Kwanisai ${ }^{1}$, Faith Chitengu ${ }^{1}$ \\ ${ }^{I}$ Travel and Recreation Department, School of Hospitality and Tourism, Chinhoyi University of Technology, \\ Zimbabwe
}

\begin{abstract}
Community involvement and support for the conservation of natural resources is a prerequisite for the long term sustainability of protected areas. Benefits' sharing has been appraised by many as an important management requirement since it can positively affect communities' perceptions of protected areas. Using the qualitative methodology this study sought to assess the extent to which the community is involved in and is benefiting from tourism in Ngezi Recreational Park. The study elucidated that community involvement was very low. There were few benefits that were available from tourism in the park which however were not evenly distributed to all community members. Little understanding of what is meant by park tourism, lack of financial resources, absence of outdoor activity culture, failure to participate in recreation or income generating activities and exclusion from park tourism management contributed to unequal distribution of tourism benefits. The paper concludes that more still need to be done to boost the level of community involvement in park tourism and recommends that the park restock its game, aggressively market the park and the activities it offers, include the community in park tourism management, and put up a trust fund to evenly distribute tourism benefits amongst community members. The findings of this study help provide a stepping stone in assessing the level of community support for protected areas which is important for wildlife conservation and tourism. Without community support, cases of poaching, habitat encroachment and hostility towards tourists may be the end result which is detrimental to the tourism industry.
\end{abstract}

Keywords: Benefits, benefits' sharing, community, conservation, protected area tourism

\section{Introduction}

The relationship between Protected Areas (PAs) and tourism offers mutual benefits which include a desirable tourism product, a source of revenue for authorities that can assist in biodiversity conservation and benefits for surrounding communities which are however sometimes associated with costs. However, it has generally been acknowledged that the establishment of many of these protected areas has worked against the direct interests of local communities [1] especially considering the exclusion of residents from natural areas and limiting their traditional consumptive use during the establishment of the protected areas [2;3]. The result has been increasing conflict between the communities and protected areas, with people developing a hostile attitude towards wildlife and wildlife conservation authorities; since they feel that exclusive preference is being given to wildlife conservation [4]. These conflicts continue to influence the communities' perceptions of wildlife, protected areas and tourism to date. Many cases of conflict between wildlife and local communities living adjacent to protected areas have been documented $[5 ; 6 ; 7]$.

Community involvement is a viable tool in resolving conflicts, and at times it facilitates tourism benefits to stakeholders. It also secures opportunities of acquiring economic benefits equally if everyone is participating in one way or the other. It is therefore vital for the community to be part and parcel of tourism in protected areas as this provides a basis for successful conservation [8]. In the face of changing social preferences, proactive measures to engage society in conservation are needed if we are to maintain broad support for protected areas.

In view of this, benefits' sharing has been considered by many as an important management requirement since it can positively affect communities' perceptions of protected areas. Communities around protected areas are seen to realise benefits from tourism in these areas $[9 ; 10]$ since management of protected areas are realising that they cannot do without community support [11]. These benefits include economic and employment opportunities [12], use of natural resources, shared decision-making and involvement in protected area management $[13 ; 14]$.

Communities which receive such benefits usually have positive perceptions of a protected area and its tourism [15]. What is worrying though is that significant benefits are rarely delivered across a wide social scale [16] where those people with the required education, skills or money to engage $[17 ; 18]$ receive the majority of benefits. Local elites, particularly men, are the ones that actively participate in and benefit from tourism in 
protected areas [19]. In most cases the wealthy, educated people who have financial resources to start tourism businesses of their own are the ones who actively participate in the tourism industry since they have access to benefits associated with these protected areas [12]. A few other ordinary community members are involved due to the fact that they are employed as guides and rangers in parks or they sell refreshments and crafts to tourists [12].

It is against this background that this study seeks to assess the level of interaction between Ngezi Recreational Park and the surrounding community and explore ways of enhancing community involvement in tourism in and around the PA.

\subsection{Tourism in protected areas}

\section{Literature Review}

Protected areas facilitate recreational activities, environmental education as well sustainable tourism [20; 21; 13; 22]. In Rwanda, tour operators have introduced community-based tourism activities such as stays with local families, village walks and banana beer production [23].

Tourism in protected areas is emerging as a development strategy because of the economic development it brings $[24 ; 25]$. Tourism in national parks contributes financially to the economy to a greater extent in terms of the revenue that is generated through visits from both local and international tourists [12]. Tourism creates employment and this makes it a perfect development strategy [14;26; 27; 28]. Locals can get jobs as park staff or start their own small business such as selling goods by the sides of the roads to tourists that would be passing by [12].

However, although tourism is good, it is also associated with other negative factors. Among them is the ownership of tourism businesses by foreigners [29;28], marginalisation of the community such that they get the low paying jobs that are of lesser importance [30], limits in the interaction of local communities and tourists due to unequal distribution of opportunities [28], exploitation or commoditisation of the local culture [30;9], and homogenisation and commoditisation of the natural environment [31].

Despite the negative impacts, when carefully planned and effectively managed, tourism can provide significant benefits to PAs and nearby communities [9], especially in developing countries that are strongly dependent on natural resources [17] and this can create a relationship between protected areas, communities and the tourism industry and also enhance community support for the tourism sector and protected areas in general.

\subsection{Community attitudes and support for PA tourism}

Local support is not necessarily vital for the survival of protected areas [32]. This is however debatable as some scholars argue that community involvement and support for the conservation of natural resources is a prerequisite for the long term sustainability of parks and protected areas [33]. The community's attitudes and perceptions are a major determinant of community support for PAs [38].

Local communities have mixed patterns towards tourism [11]. Communities that benefit from tourism show a positive attitude and support for tourism. They see tourism as a way to satisfy their economic needs or desires, or to associate themselves with the privileged lifestyles displayed by tourists [34]. Unequal sharing of the benefits of tourism within a community can also cause dissatisfaction among segments of the communities [35]. An important cause for negative attitudes towards tourism is community involvement in decision-making [36]. Communities that are involved in decision-making regarding tourism have a more positive attitude towards tourism. The attitude of locals towards tourism development can influence the success or failure of tourism. Dissatisfaction leads to hostile attitudes that scare tourists away from an area [37].

Some communities who show an understanding of what their area offers in terms of attractions have positive attitudes towards tourism. Usually those communities who reside nearest to protected areas and who have borne most of the costs of exclusion appear to participate least in the tourism industry [12].

Communities see tourism as an attractive potential source of income, but few would be willing to give up their current livelihood if they were to take on a tourism-related job [38]. The employment opportunities created through tourism development tend to favour women and youth [35; 39] although some communities express some apprehension about societal opinions and safety of such jobs [38]. There is an open attitude towards the involvement of women and ethnic minorities in tourism jobs. Women and men are seen as equally suitable for leadership roles in tourism development and enterprise. Concerns by some members of the communities are that women and girls who work in guest houses and restaurants are judged negatively by society although others who express a more positive attitude think that communities should be more receptive to change [38]. 


\subsection{Study context}

\section{Methodology}

Ngezi Recreational Park was declared a national park in 1952 and is fully protected under the Parks and Wildlife Act. The park is 6326 hectares in extent of which 573 hectares are occupied by the Ngezi dam. Several species of game are found in the park which includes antelope, hippos, kudus, zebras, waterbucks and rhinos. The park is divided into two sections, one section is where fishing and water related recreational activities take place and the other is mainly for wildlife tourism. There are 25 campsites, a caravan site in the park and self catering lodges and chalets. Tourist activities in the park include walking safaris, fishing, bird watching and game drives.

\subsection{Data collection and analysis}

The study employed the exploratory design. Open-ended questionnaires and in-depth interviews were used. The case study approach was also used to facilitate a detailed investigation of local experiences within their real life context. The target population for this study was the Parks and Wildlife Authority management in Ngezi Recreational Park and the surrounding community. The community comprised of four villages living around Ngezi Recreational Park with 371 hoseholds in total: Manyoni (85), Village 7 (49), Silverstar (104) and Bumbe (133). 75 participants were randomly selected for the survey. Lists of all household members in each village were obtained from the village headmen. All the names of household heads in a village were put in a hat and a specific number of names were randomly picked from the hat. 17 participants were chosen from Manyoni village, 10 from Village 7, 21 from Silverstar, and 27 from Bumbe village and these represented about $20 \%$ of the total households in each village.

Nine personal interviews were conducted with Parks and Wildlife Authority employees to gain an indepth understanding of the level of community involvement in tourism and park tourism management as well as the amount of benefits they get from park tourism. Open-ended questionnaires were used to solicit information from the community.

Household heads or other permanently resident adults ( $\geq 18$ years) were interviewed. Questionnaires were hand delivered to respondents in their own homes. Data were collected between April and May 2013. Thematic approach was used to analyse the data.

\subsection{Response rate}

\section{Findings and Discussion}

\begin{tabular}{|l|l|l|l|l|}
\hline Village & $\begin{array}{l}\text { Total number of } \\
\text { households }\end{array}$ & Targeted households & Responded households & $\begin{array}{l}\text { Response rate } \\
\%\end{array}$ \\
\hline Manyoni & 85 & 17 & 15 & 88 \\
\hline Village 7 & 49 & 10 & 10 & 100 \\
\hline Silverstar & 104 & 21 & 20 & 95 \\
\hline Bumbe & 133 & 27 & 19 & 70 \\
\hline Total & 371 & 75 & 64 & 85 \\
\hline
\end{tabular}

75households/ questionnaires were targeted for the study and 64 actually managed to complete the questionnaires. Those households where no member above the age of 18 was present were left out. The overall response rate for all the villages was $85 \%$ and was considered adequate for the study.

\subsection{Demography of respondents}

The respondents consisted of $51 \%$ males and $49 \%$ females. About $84 \%$ of the residents interviewed were permanent residents of the area while $16 \%$ were temporary residents. $49 \%$ of the respondents had lived in the village for a period of 10 years and below, $14 \%$ had lived in the area for a period between 11-20 years and the remaining 37\% had lived around Ngezi Recreational Park for more than 20years. About $29 \%$ of the respondents lived $2 \mathrm{~km}$ away from the park boundary, $39 \%$ lived $2-5 \mathrm{~km}$ away from the park boundary, $20 \%$ were within the range $6-10 \mathrm{~km}$ away from the park boundary and the remaining $12 \%$ lived more that $10 \mathrm{~km}$ away from the boundary. $18 \%$ of the questionnaire respondents revealed that they worked in the tourism industry, $20 \%$ worked in mining, $31 \%$ depended on subsistence agriculture, $8 \%$ depended on fishing, $6 \%$ were entrepreneurs while $14 \%$ had other sources of income i.e. teaching, working in the shops, hairdressing and working in the Information and Technology sector. $57 \%$ of the respondents had attained up to secondary level education, $22 \%$ only had primary education, $15 \%$ had gone up to tertiary education and only $6 \%$ had gone up to high school. 


\subsection{State of tourism in the park}

All the park respondents confirmed that the park had witnessed a decline in tourist arrivals in the past five years. This had been attributed to the dwindling numbers of the animals in the park. The park had very few animals at the time of the study, making it less attractive to tourists. Again, the decline was also linked to the poor state of the tourism facilities such as accommodation which needed renovation if they were to meet acceptable standards. The furniture had become old and there was need for a more modern touch up or at least replacement so that guests could stay comfortably. Majority of the community members expressed sadness, disappointment and worry because of the decline in the number of tourists visiting the park. Recent years had seen an unfavourable pattern in the park's tourism trends.

\subsection{Interaction between the Park and the community 4.4.1 Entry into the park}

Majority of the respondents acknowledged that the park was easily accessible to them as they could either walk to the park or use public transport passing through the park. Problems only arose in the rainy season because there are gravel roads only in the area. However, about $14 \%$ of the respondents expressed difficulties in visiting the park due to the "high" entry fees that was required by the Park. Because of the "high" entry fees a number of respondents confirmed that they entered the Park unlawfully because there is no tight security around the Park.

\subsubsection{Purpose of visiting the Park}

$8 \%$ of the respondents pointed out that the major reason why they visited the park was fishing for either leisure or business as well as fishing to supplement their diet. Those who did fish for recreation were the communities residing in the Turf (Village 7) area who had well paying jobs in the mines. Apart from fishing they also took part in game drives, camping, walking trails and bird watching. People living close to the park usually visited to collect firewood, look for their stray livestock, picking up mushroom, cutting grass, driving stray wild animals back to the park as well as visiting friends and relatives. There were a few (4\%) others who passed through the park on their way to neighbouring villages for various reasons. Others visited the park to conduct businesses such as boat rental, selling worms, fishing rods and nets. The findings indicate minimal tourism-related motivation for visiting the park.

\subsubsection{The relationship between the park authorities and the communities}

Four respondents from the Park described the Park's relationship with the community as slightly above average, three respondents said it was good and two respondents said the relationship was poor. Six of the park officials said the Park Management Plan does not stipulate community involvement in management and accrual of benefits from the park. However three of them said in some situations the communities were involved and their views were considered but most of the time the park operated independently from the communities. This kind of set up might be a result of unclear structures or guidelines for community integration into the park's tourism activities. A large proportion of the world's protected areas are government-run and, with stretched budgets and their management is often problematic [2]. This may be the major reason why majority of the respondents from the community felt that the park authorities alienated them from management of park tourism and benefits sharing issues.

About $83 \%$ of respondents from the community revealed that they were always at loggerheads with the park especially those who live closest to the park. Most of them complained that the animals were destroying their crops and this negatively impacted on them since they are subsistence farmers. Fortunately the park personnel were said to be very responsive, when notified of animals that would have escaped from the park into the neighbouring villages, they promptly got into the villages to capture the animals. The wild pigs, kudus and baboons were among the problem animals that often went into the villages.

This issue of human-wildlife conflict has resulted in some villagers killing the animals that escape from the park in the process of safeguarding their agricultural produce which they mainly rely on as their source of food and for selling to the park employees and tourists. Local communities said the park is not being strict enough with the animals.

\subsubsection{Support for park tourism and conservation}

$100 \%$ of the respondents from the community indicated that they were in support of tourism. The communities also accepted tourists since their presence kept the park going. They even assisted when the park was affected by veldt fires. One community member actually said: take place".

"We help out in the fire because it is our responsibility. We feel obliged to assist when such mishaps 
All the respondents from the park rated the local communities support for tourism in the park as generally average and confirmed that there were some members of the community who had never visited the park or never taken part in any tourism activities that take place in the park. All the respondents from the park also said the communities were involved in tourism related activities in the park. About $56 \%$ of the respondents from the community acknowledged that they were involved in some tourism activities in the park and they value the benefits that tourism brings. The community members said they were involved in small businesses such as selling agricultural produce, worms and renting out their boats from which they got money to buy groceries and pay school fees for their children.

However, about $30 \%$ of the respondents from the community had mixed feelings towards the park, tourism and tourists who visited the park. They said that they felt left out since the park authorities did not consult them concerning some crucial matters that affect their lives. Some of them viewed the park as an expense to them as they had to pay money to redeem their livestock when they entered the park and this brew conflict between the park and communities. Majority of the communities however were in support of conservation in the park. About $92 \%$ expressed their desire to conserve wildlife for future generations. One community member said:

"It is good to conserve wildlife. Our children might be able to see the wildlife and benefit from these areas through employment opportunities as well".

Another community member from Manyoni village commented:

"The Park is important to me and my family. The Government should tighten regulations governing the protected areas to ensure their survival".

It was clear from the study that the local communities were aware of the importance of conserving nature. In the case of Ngezi Recreational Park, the realisation came a bit too late as a number of the animals had already been killed by the villagers for "trespassing." All respondents from the park confirmed that the communities were taking part in conserving both the wildlife and the natural environment in the park. They acted as watchdogs for the park, reporting any suspicious behaviour related to poaching. In some cases they would directly report professional poachers to the park authorities. The incentives that some members of the communities got encouraged them to take part in conserving the resources. The majority of the respondents from the community suggested that there was need to introduce more effective methods of conservation because of the park's vulnerability to poachers. Because the park's fence was stolen, it was very difficult to keep the animals inside the park and some of the animals were killed when they strayed out of the park. Although fencing can reinforce perceptions of separation through being a physical as well as psychological barrier to local entry [40], majority of the respondents said it was safer for them as it provided protection from the park's animals. One community member had this to say:

"The park should replace the fence. It will be a saviour to us because we are always in constant battle with the wild animals".

\subsection{Community benefits from tourism \\ 4.5.1 Local employment creation}

$18 \%$ of the respondents from the community said they looked up to tourism for livelihood. They indicated an appreciation of the economic benefits derived from employment in park tourism, with many respondents linking employment opportunities to survival and a better life. One park official confirmed that the park's total permanent work force comprised of $17 \%$ from the community. Their job positions ranged from rangers to lodge attendants. Many others were employed on a contract basis for instance, when there was need to put up a fireguard or thatch the chalets and the jobs usually earned them very low wages. Other protected areas were also found to provide jobs for the communities [41]. Employment is one of tourism's main development advantages and its role in promoting economic opportunities for communities adjacent to parks has long been appreciated [28; 26]. The tourism industry through protected areas can improve the lives of many communities if the jobs have some form of security. Employment offers a clear means of community involvement and benefits from tourism in the park. The availability of employment opportunities triggers more support and participation in tourism [12].

\subsubsection{Other benefits}

About $39 \%$ of the respondents from the community said that the park provided opportunities to conduct business such as boat rental, selling worms, fishing rods and nets. Entrepreneurship in the communities actually emerged as a result of tourism although the businesses were on a small scale. One member of Manyoni village owned a boat that is hired by tourists in the park when the need arises. Another member from Silverstar was into the business of selling fishing worms. Most of the women sold vegetables and fresh farm produce to the tourists since the park offered self-catering accommodation. 
The park also provided intangible benefits to the community. Almost 53\% said that the park provided socio-cultural links amongst the communities themselves as well as tourists from other places. To some members of the community, the park was described as a source of pride, they felt proud to be associated with it. About 28\% said that the park offers them the opportunity to interact with the tourists. On the brighter side, tourism can contribute to cultural exchange and to revitalising old cultures, traditions, languages and arts [24].

\subsubsection{The distribution of tourism benefits}

Six respondents from the park said the communities were failing to benefit from tourism in the park because they did not participate in recreation or income generating activities that might deduce some revenue from the parks activities such as selling agricultural produce. $29 \%$ of the respondents from the community pointed out that they were not benefiting anything because the park excluded them from its operations so all chances of getting benefits were shattered. Inequities in benefit distribution typically result from restricted opportunities for locals and tourists to interact thereby reducing the chances of benefiting from tourism [28].

\subsubsection{Expectations of the community}

The majority of the respondents from the community said they expected the park to provide some social benefits from the tourism proceeds which included schools, boreholes and hospitals. Many years down the line tourism still has not brought any significant changes to communities surrounding the park. Respondents indicated that they needed the proceeds from tourism to be used to develop the living standards in the community. A few community members had the following comments to make:

"The tourists bring in money. At least the park should assist in building up a primary school. Our children, some as young as six, walk for $10 \mathrm{~km}$ or more everyday to attend lessons at Guzuzu Primary school",

"The so called benefits are failing to materialise. We don't have protected water for cooking and drinking and we are still relying on unprotected sources of water",

"We need the park to assist us by constructing a clinic in the area because if someone gets attacked by a hippo they have to travel a very long distance to get to get to the hospital".

Decision making, planning and consultation to do with tourism and benefits that can be accrued were other areas that the villagers expected the park authorities to address. This could be made possible through frequent meetings with the park authorities. Only $39 \%$ of the respondents said that the park authorities considered them when dealing with issues related to tourism in the park. The communities expected to have a more active role and be able to make decisions since the activities that take place in the park affected them. They also expected more job opportunities from the park to enable them to have better lives.

The financial benefits of tourism are often being overstated, leading to conflict over unmet expectations [42]. Expectations of the communities need to be considered to avoid conflict in protected areas therefore leading to resentment of these areas, negative attitudes towards tourism and tourists as well as habit encroachment [28].

\subsection{Barriers to community participation in tourism related activities}

Most of the people in the community were failing to take part in tourism because of the following reasons:

- About $11 \%$ the respondents acknowledged that they did not quite understand what tourism is all about so it would be very difficult for them to engage even if they were given the chance to participate in tourism. Some of them also did not know that they could take part in tourism activities in the park; they thought the park was an independent entity from the community.

- The majority of the respondents (56\%) lacked financial resources. They expressed the desire to start up tourism businesses in the area but the limited availability of money hindered them. Others would want to participate in recreation but they also lacked money to pay for the recreational activities in the park.

- Majority of the respondents (78\%) indicated lack of a culture for outdoor activities. They simply found no reason why they should engage in outdoor activities for leisure.

These barriers are synonymous to other communities adjacent to different protected areas as well. Lack of community capacity in terms of business and management skills is commonly cited as a barrier for community participation in park tourism [40]. In the tourism industry, typically those people with the required education, skills or money to engage are the ones who take part and receive the majority of benefits [18].

\section{Conclusions}

The study showed that the residents of the communities under study looked up to farming and mining mainly for their livelihood. There are a few others who depended on the park for commercial fishing. There were some fishing cooperatives around the park and their involvement was mainly on the commercial side rather than that of leisure. To the community, tourism did not seem to offer many options for them in terms of livelihood. This was exacerbated by the low levels of tourist arrivals that the park was experiencing. The 
community perceived mining and farming as offering better options. However, a few members of the community were benefiting from the park and were satisfied with what they were getting.

It was also evident that the local communities were in support of nature conservation. $100 \%$ of the community members said they liked the idea of conserving nature although some of the park officials said some of the villagers did not appreciate nature. Even though the community was restricted access to natural resources such as veldt grass for thatching, fish, mushroom and firewood, they still valued the importance of conservation and the existence of protected areas.

The participation of local communities in decision making, recreational activities and other tourism related activities was generally low since they were not usually consulted and had very little income to engage in recreation or start up tourism business. Others were not aware that they were free to do businesses in the park as long as they sought approval first.

A number of respondents also pointed out the need for more job opportunities in the park so that the communities can earn a living. This could be made possible if the park ventures into partnership with the private sector to improve its operations. More jobs could be created then. Only a few people have benefited from employment creation in the park.

In a nutshell, there were a few benefits available from tourism in the park but not all of the communities were getting them. Only those who take part in activities related to the park get the majority of the benefits. More needs to be done about the level of community involvement because it is low.

\section{Recommendations}

Based on the findings and conclusions, the paper makes the following recommendations to enhance the community's involvement and increase the level of benefits they get from tourism:

- The park may need to restock its game to make it more attractive to tourists. Restocking will bring life into the park and the number of tourists visiting the park may increase.

- There is need for the park to engage in partnership with the private sector so that necessary funding that is needed to revamp the park can be obtained. Since the park is wholly managed by the government, the budgets are always strict and issues such as refurbishing the guest accommodation might be regarded as not very critical. Again funding from the private sector is also necessary as it will give the communities higher chances of playing an active role in the park operations as more people would be recruited to ensure the smooth running of the park as there are few employees in the park at the moment.

- There is also need to aggressively market the park and the activities that it offers. Very few people know about the park and that could be one of the reasons why its tourist arrivals are relatively low. The park could first focus on the domestic market as this market is the backbone of tourism in any destination. More tourists will give the communities more chances of starting up tourism related businesses hence more benefits to the local community.

- More recreational activities need to be introduced in the park. The park is still almost offering the same activities it was since it opened i.e. camping, game drives, walking trails, bird watching and fishing. Some of the activities are no longer taking place as there is shortage of important resources such as lifeguard jackets for water related activities. There is therefore need to introduce more activities in the park.

- Community awareness campaigns should be held with particular focus on what tourism is all about and the benefits that it can bring to the local communities. The campaigns should also aim at encouraging local communities to take part in tourism in the park or recreational activities.

- Local leadership such as village heads should also be included in the tourism management plan as they have great influence on the people that they lead. This will promote cooperation amongst the local communities and reduce conflicts that may arise between them and the park.

- There is need to put up a community trust fund so that the benefits from tourism can be evenly distributed amongst the community members. The proceeds can be used to erect boreholes, clinics and schools thus benefiting everyone in the community.

- Training of the local communities is also another step that can be taken so that they can be employable in better paying job positions in the park. The training can help them to start something of their own tourism businesses or partner with those who have the necessary start up capital.

- Ongoing research should be carried out to find out if there are any changes in the level of involvement amongst the communities in tourism in the park and checking whether there are any changes concerning the distribution or accrual of benefit from tourism.

\section{References}

[1] E. Barbier, and C. Burgess, The Economics of tropical deforestation, Journal of Economic Surveys 15(3), 2001

[2] M. Novelli and A. Scarth, Tourism in Protected Areas: Integrating Conservation and Community Development in Liwonde National Park (Malawi) (Centre for Tourism Policy Studies, University of Brighton,UK, 2009). 
[3] K. Doohan, Making things come good: Relations between Aborigines and miners at Argyle (Broome: Backroom Press, 2008).

[4] L. Mhlanga, Conflict Between Wildlife and People in Kariba Town, Zimbabwe, Zambezia, $28(1), 2001$.

[5] R.K. Hawkes, Crop and livestock losses to wild animals in the Bulilimamangwe Natural Resources Management Project Area (Harare, University of Zimbabwe, Centre for Applied Social Sciences, 1991, Unpublished).

[6] M. Murphree, Communities as Resource Management Institutions (Harare, University of Zimbabwe, Centre for Applied Social Sciences, 1991, Unpublished).

[7] S.K. Nepal, and K.Weber, Struggle for existence: park-people conflict in the Royal Chitwan National Park, Bangkok, 1995.

[8] N. Baral, J.T. Heinen, M.J. Stern, Integrated conservation and development project life cycles in Annapurna Conservation Area, Nepal: Is development overpowering conservation? International Journal of Biodiversity and Conservation, $16,2007$.

[9] P.F.J. Eagles, and S.F. McCool, Tourism in national parks and protected areas: planning and management (Wallingford: CABI Publishing, 2002).

[10] G. Wall, and A. Mathieson, Tourism: Changes, impacts and opportunities (New York: Pearson Prentice Hall, 2006).

[11] N. Sekhar, Local people's attitudes towards conservation and wildlife tourism around Sariska TigerReserve, India, Journal of Environmental Management, 69, 2003.

[12] J.K. Strickland-Munro, S.A. Moore and S. Freitag-Ronaldson, The impacts of tourism on two communities adjacent to the Kruger National Park, South Africa, Development Southern Africa, 27(5), 663-678, 2010.

[13] S. Stolton, Communicating Values and benefits of protected areas in Europe, Seminar, Germany Federal Agency for Nature Conservation, Germany, 2009.

[14] L.M. Scherl and S. Edwards, Tourism, indigenous and local communities and protected areas in developing nations in R. Bushell and P.F.J. Eagles (Eds.), Tourism and protected areas: Benefits beyond boundaries (Wallingford: CABI International, 2007) 71-88.

[15] P. Figgis and R. Bushell, Tourism as a tool for community-based conservation and development in R. Bushell \& P.F.J. Eagles (Eds.), Tourism and protected areas: Benefits beyond boundaries (Wallingford: CABI International, 2007) 101-114.

[16] M.C. Simpson, An integrated approach to assess the impacts of tourism on community development and sustainable livelihoods, Community Development Journal, 44(2), 2009.

[17] C. Tosun, Limits to community participation in the tourism development process in developing countries, Tourism Management, 21(6), 2000.

[18] A. Trau, and R. Bushell, Tourism and indigenous people in S.F. McCool \& R.N. Moisey (Eds.), Tourism, recreation and sustainability: Linking culture and the environment (Wallingford: CAB International, 2008).

[19] R. Scheyvens, Ecotourism and the empowerment of local communities, Tourism Management 20(2), 1999.

[20] C. Bitapi, S.Q. Qureshi, V.K. Uniyal and S. Sen, Economics of wildlife tourism contribution to livelihoods of communities around Kanha Tiger Reseve, India, Journal of Ecotourism, 2012.

[21] Y.V. Jhala, R. Gopal, and Q. Qureshi, Status of tigers, co-predators and Prey in India (TR08/001, Dehradun, India: Wildlife Institute of India, 2008).

[22] M. Van der Merwe and A. Wocke, An investigation into responsible tourism practices in the South African hotel industry, South African Journal of Business Management, 2008.

[23] Nielsen and Spenceley, World Bank: Country Assistance Strategy for the Republic of Rwanda for the Period FY09-FY12 (Report No. 44938-RW, Washington, DC, 2011).

[24] D.J. Telfer and R. Sharpley, Tourism and Development in the Developing World (Routledge, London, 2008).

[25] M. Uysal, C.D. Mcdonald and B.S. Martin, Australian visitors to US national parks and natural areas, International Journal of Contemporary Hospitality Management, 1994.

[26] T.S. Simelane, G.I.H. Kerley and M.H. Knight, Reflections on the relationships between communities and conservation areas of South Africa: The case of five South African national parks, Koedoe 49(2), 2006.

[27] C. Ashley and D. Roe, Making tourism work for the poor: Strategies and challenges in Southern Africa, Development Southern Africa 19(1), 2002.

[28] P. Goodwin, Local Community Involvement in Tourism around National Parks: Opportunities and Constraints, Current Issues in Tourism, 5(3-4), 338-360, 2002.

[29] J.E. Mbaiwa, Enclave tourism and its socio-economic impacts in the Okavango Delta, Botswana, Tourism Management, 26, 157$172,2005$.

[30] B. Archer, C. Cooper and L. Ruhanen, The positive and negative impacts of tourism in W.F. Theobald, (Ed.), Global Tourism (Butterworth-Heinemann, Oxford, UK, 2005).

[31] J. Saarinen, Tourism in the northern wildernesses: wilderness discourses and the development of nature based tourism in northern Finland in M. Hall and S. Boyd (Eds), Nature-Based Tourism in Peripheral Areas: Development or Disaster? (Clevedon: Channel View Publications, 2005).

[32] D. Brockington and K. Schmidt-Soltau, The social and environmental impacts of wilderness and development, Oryx, $38,2004$.

[33] E. Fiallo and S. Jacobson, Local Communities and Protected Areas: Attitudes of Rural Residents Towards Conservation and Machalilla National Park, Ecuador, Environmental Conservation, 22, 2011

[34] D. Connelly-Kirch, Economic and social correlates of handicraft selling in Tonga, Annals of Tourism Research 9(3), 383-402, 1982.

[35] E. De Kadt, Social planning for tourism in the developing countries, Annals of Tourism Research 6(1), 36-48, 1979.

[36] P. Murphy, Tourism: A Community Approach (Routledge: New York, 1985).

[37] WTO, Indicators of Sustainable Development for Tourism Destination: A Guidebook (World Tourism Organization: Madrid, 2004).

[38] W. Suntikul, T. Bauer and H. Song, Towards Tourism: a Loatian Perspective, International Journal of Tourism Research 12, 449$461,2010$.

[39] G. Nyaupane, D. Morais and L. Dowler, The role of community involvement and number/type of visitors on tourism impacts: a controlled comparison of Annapurna, Nepal and Northwest Yunnan, China, Tourism Management 27(6), 1373-1385, 2006.

[40] J. Strickland-Munro and S. Moore, Indigenous involvement and benefits from tourism in Protected areas: A study of Purnululu National Park and Warnum Community, Australia, Journal of Sustainable Tourism, 21(1), 26-41, 2013.

[41] K. Hornberger and H. Nevill, Should we be promoting tourism sector investment? (The World Bank - Working for a world free of poverty, 2011).

[42] C. Fabricius, E. Koch and H. Magome, Towards strengthening collaborative ecosystem management: Lessons from environmental conflict and political change in southern Africa, Journal of the Royal Society of New Zealand 31(4), 831-44, 2001. 